\title{
Environmental migration and country security: Theoretical analysis and empirical research
}

\author{
Iryna Didenko ${ }^{1 *}$, Kseniia Volik $^{2}$, Tetiana Vasylieva $^{3}$, Serhiy Lyeonov ${ }^{4}$ and Nataliia Antoniuk ${ }^{5}$ \\ ${ }^{1}$ Sumy State University, Economic Cybernetics Department, 40000 Sumy, Ukraine \\ ${ }^{2}$ Sumy State University, Department of Economics, Entrepreneurship and Business Administration, 40000 Sumy, Ukraine \\ ${ }^{3}$ Sumy State University, Department of Finance and Entrepreneurship, 40000 Sumy, Ukraine \\ ${ }^{4}$ Sumy State University, Economic Cybernetics Department, 40000 Sumy, Ukraine \\ ${ }^{5}$ Sumy State University, Department of Finance and Entrepreneurship, 40000 Sumy, Ukraine
}

\begin{abstract}
The article considers the impact of environmental changes on population migration and security of countries. Theoretical aspects of Environmental migration, in particular its essence and types, are studied. The main directions of scientific research in this field are considered. In particular, much attention is about finding ways to adapt to changes in the environment and minimize the negative consequences of these changes to achieve sustainable development in both regions and countries. The study found that internal population movements are mainly due to climatic factors such as storms and floods. It was determined that in 2019, about $52 \%$ of new mixing was caused by storms and $40 \%$ - by floods. Countries for which the phenomenon of ecological migration is most characteristic are India, the Philippines, the United States, China, and Indonesia. The main problems that arise in the study of Environmental mobility of the population are identifiedThey are mainly related to the lack of information and statistical base for conducting qualitative and diverse research.
\end{abstract}

\section{Introduction}

Ensuring the security of the country is perhaps the most crucial task facing states and their unions. Stable socioeconomic development of society is impossible without a coordinated policy of the state aimed at protecting its interests. An important element in the implementation of this policy is the regulation of migration processes, as human resource mobility can lead to disparities in the structure of the demographic potential of both donor and recipient countries, which can pose a threat to national security. An important element in the study of migration processes is the study of migration due to environmental consequences because the state of the environment forces people to leave their homes and seek new asylum, sometimes even outside their country.

The work aims to analyze the theoretical aspects of ecological migration, study its impact on national security, assess the quantitative indicators of this phenomenon, and identify problems that complicate its analysis.

There are a lot of scientific works about environmental factors that are the driving force of internal and external migration around the world and a threat to national safety [1-5]; the indirect factors influencing climate and safety, including the impact of agriculture, food prices, economic growth, migration, disasters, money laundering, international and domestic institutions [6-10].
The opinion of a group of scientists about the consideration of Environmental migration is from the standpoint of a social phenomenon. [7-8].

Another group of studies that are singling out is the study of strategies for adapting to climate change to protect environmental migrants from ensuring the country's safety of the country [9-10].

Among the research, areas are aimed at analyzing environmental indicators to build a balanced policy to ensure the safety of the country, particularly in ecology, energy, and food [11-13]; the impact of population migration on the safety of countries [14] and the impact of migration in rural areas in terms of sustainable development [15-18].

\section{Methodology}

This work aims to study the theoretical aspects of the relationship between environmental migration and national security and conduct an empirical study of the extent of environmental migration by reviewing the Internal Displacement Monitoring Center's annual reports.

The study of the authors' publishing activity in the direction of studying issues related to the country's ecological migration and security is based on the information presented in the scientometric database "Scopus". The systematization of views will make it possible to identify the most relevant research areas in this area.

\footnotetext{
* Corresponding author: iryna.didenko2011@gmail.com
} 
Vosviewer software is used to analyze bibliometric networks of authors belonging to certain countries. This analysis will conspire to see the relationship between countries in the study of the study and to identify the countries that have committed the most in the study of issues related to migration due to environmental changes and security.

Statistical analysis of the dynamics and structure of internal movements of people due to changes in the environment will allow us to assess the significance and significance of this phenomenon both for the countries where they occur and for humanity as a whole.

\section{Results and Discussion}

Nowadays, environmental problems are significant to humanity because they pose a potential threat to human life and health. Such problems include natural disasters, environmental pollution due to anthropogenic factors, global climate change, irrational use of natural resources, and others. Many catastrophes in the world are directly related to the environment. Example:

- The Chernobyl disaster of 1986;

- accident at the Fukushima nuclear power plant in Japan in 2011 due to a tsunami caused by an earthquake;

- Bhopal disaster in India in 1984, caused by a leak of highly toxic gas at a chemical plant;

- Tien Shan earthquake in China in 1976;

- earthquake in Sichuan, China, in 2008;

- Hurricane Katrina in the United States in 2005;

- Hurricane Harvey, USA, 2017, etc.

This list is not a complete list of disasters that have caused significant damage to the environment. It is important to note that in addition to human casualties and significant destruction, one of the consequences of these catastrophes is a significant migration of people from areas that become unfit for healthy life.

Millions of people around the world are moving in anticipation of, or response to, environmental change. Cyclones, floods, hurricanes, fires, sea level measurements destroy homes and assets, contributing to this movement.

The leading causes of environmental nature that cause migration:

- natural disaster, which has become a major environmental disaster;

- the man-made environmental incident, which is characterized by the severity of the damage to the environment, ie, such events may acquire signs of environmental disaster and not cause severe damage to the environment;

- deterioration of the Environmental environment, which is caused by irrational use of nature and illconsidered human activities;

- early notification of the population about the possibility of natural [19].

The impact of climate change on migration can manifest itself in two ways, depending on the time sign:
- long-term climate processes (sea-level rise, salinization of agricultural land, desertification, soil erosion, water scarcity);

- short-term extreme climate events and extreme weather events (flooding, hurricanes, storms, etc.) [20].

The mechanism of environmental impact on migration is quite complex, as it must also take into account economic, political, cultural, and demographic factors that influence a person's decision to move.

The International Organization for Migration (IOM) proposed the following definition: "Environmental migrants are persons or groups of persons who, for compelling reasons of sudden or progressive changes in the environment that adversely affect their lives or living conditions, are obliged to leave their habitual homes, or choose to do so, either temporarily or permanently, and who move either within their country or abroad" [21] for people who are moving for environmental reasons,. This term covers all types of human movements, because Environmental migration can be both voluntary and forced, take place within the country, or have an international level. Temporarily, this type of migration can be permanent or temporary. It should be noted that the term "environmental migration" proposed by the IOM is not normative. It is a working definition that describes the relationship between the adverse effects of environmental change and migration.

Environmental migrants can be divided into three types:

- environmental emergency migrants - people who are temporarily fleeing due to an environmental disaster or sudden environmental event, such as a hurricane, tsunami, earthquake, etc .;

- environmentally displaced people - people who have to leave due to deteriorating environmental conditions and the state of the environment, such as deforestation;

- environmentally motivated (environmentally induced economic) migrants - people who decide to leave to avoid possible future problems in the environment, an example is the departure due to reduced yields caused by droughts [22].

It is worth noting that the concept of internally displaced persons is quite close in importance to environmental migrants. According to the United Nations Office for the Coordination of Humanitarian Affairs (UNOCHA) "Internally displaced people (IPDs) - persons or groups of persons who have been forced or obliged to free or to leave their homes or places of habitual residence, in particular as a result of or to avoid the effects of armed conflict, situations of generalized violence, violations of human rights or natural or human-made disasters, and who have not crossed an internationally recognized State border" [23].

These concepts are not identical, but they have something in common, among other features that describe the mobility of people under the influence of changes in the country's environment. Thus, no matter what the phenomenon is called, it exists and needs further study.

Changes in the environment affect the processes of human movement and threaten the country: 
- catastrophes and related displacements place an additional burden on the country's financial system, as additional financial resources are needed to combat the consequences of these phenomena;

- there is an additional burden on the social sphere of the country, associated with the mass provision of minimum social guarantees to people who were forced to leave their homes. The number of unemployed is growing;

- limited food, resource, and energy security can provoke armed conflicts, threatening the unity and national security of the country;

- large areas temporarily or permanently become unfit for economic activity, which affects the country's economy;

- if external Environmental migration is manifested, then the emergence of social tensions in society in the form of conflicts on national and religious grounds is not excluded;

- increase in criminogenic stress;

- growing social inequality between victims of environmental migration and the rest of the population;

- Environmental pollution of territories threatens human safety, life, and health, etc.

The literature review of research conducted in the field of Environmental migration and security of the country was carried out using bibliometric analysis of the scientometric database Scopus as one of the most significant abstract databases, which indexes about 24 thousand scientific journals. In total, for the period 19882019, Scopus found 595 publications on the keywords "environmental change", "climate change", "environment", "migration", "displacement" and "security" in such fields of knowledge as Social Sciences, Environmental Science, Economics, Econometrics, Finance, Business, Management, Accounting, Art and Humanities, etc. Analysis of publishing activity has shown that in the last decade, there has been a growing interest in researching the issue of the country's environmental migration and security, which is reflected in the increasing number of publications related to this issue (Fig. 1). If before 2009, an average of 5 articles were published per year, then since 2009 , the average number of publications per year is 44 .

If we consider the publishing activity of the authors by country (Fig.2), the largest centers of research on this issue are the United Kingdom, the United States, Canada, and Germany. Figure 2 shows the relationship between countries in terms of cooperation in the study of the research question. The more often countries cooperate, the thicker the lines between them.

The following are the main areas of research conducted in the field of Environmental migration and security of the country:

- identification of the impact of the environment on Environmental migration and security of the country [2428];

- $\quad$ research of possibilities of adaptation of territories to changes of the environment [29-33];

- $\quad$ study of social vulnerability to climate change [34$36]$;
- $\quad$ analysis of the impact of environmental migration on the emergence of conflicts in developing countries [3740];

- $\quad$ study of ways to achieve sustainable development in a changing climate, environmental change, and migration [41-45];

- consideration of African and Asian regions as the most prone to Environmental migration, etc. [37, 46].

Thus, Environmental migration affects various areas of activity, which indicates the importance of its further study.

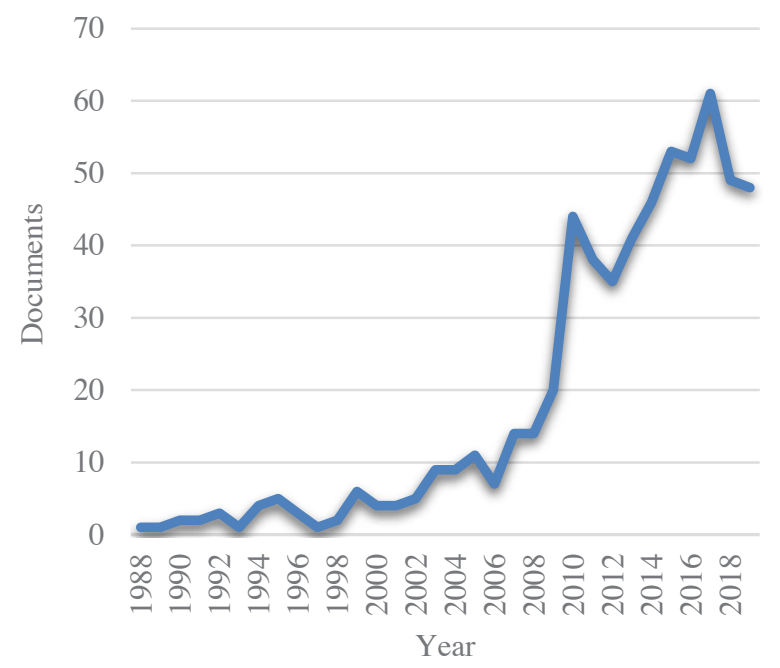

Fig. 1. Dynamics of publishing activity in the field of Environmental migration and security of the country in Scopus

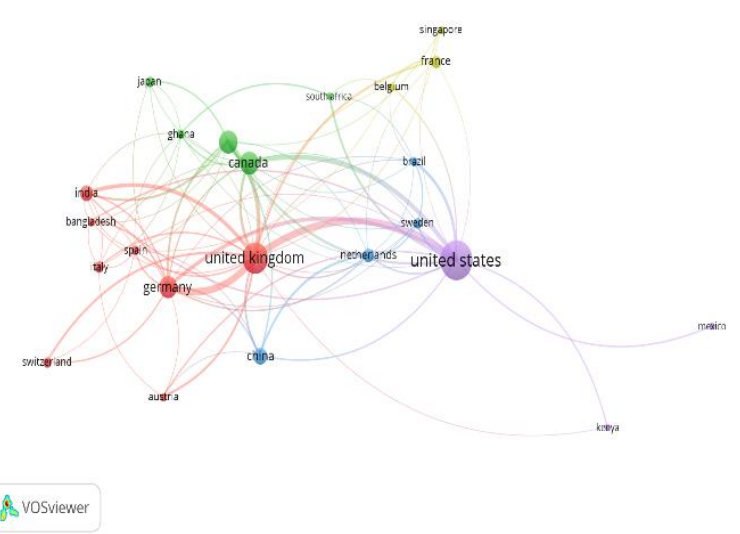

Fig. 2. Relationships between countries in the study of issues related to environmental migration and security

The next step of the study is the analysis of internal migration provoked by environmental factors.

According to the Internal Displacement Monitoring Center (IDMC), in 2018, there were 17.2 million cases of new internal displacement of people related to disasters in 148 countries and territories. These figures do not take into account the millions of people who have been displaced by previous cataclysms. In particular, the largest number of cases of displacement due to disasters 
was recorded in the Philippines (3.8 million), China (3.76 million), India (2.68 million), the United States (1.25 million), Indonesia (853 thousand) and Nigeria. 613 thousand) (Fig. 3) [47].

In 2019, the number of relocations carried out as a result of catastrophes amounted to 24.9 million people, $44.8 \%$ more than in 2018. The largest number of movements was observed in India (5 million), Bangladesh (4 million), the Philippines (4 million), China (4 million), the United States (0.92 million), Iran (0.5 million), Mozanbiku (0.5 million). million), Ethiopia ( 0.5 million) and Somalia (0.48 million) (Fig. 4) [48].

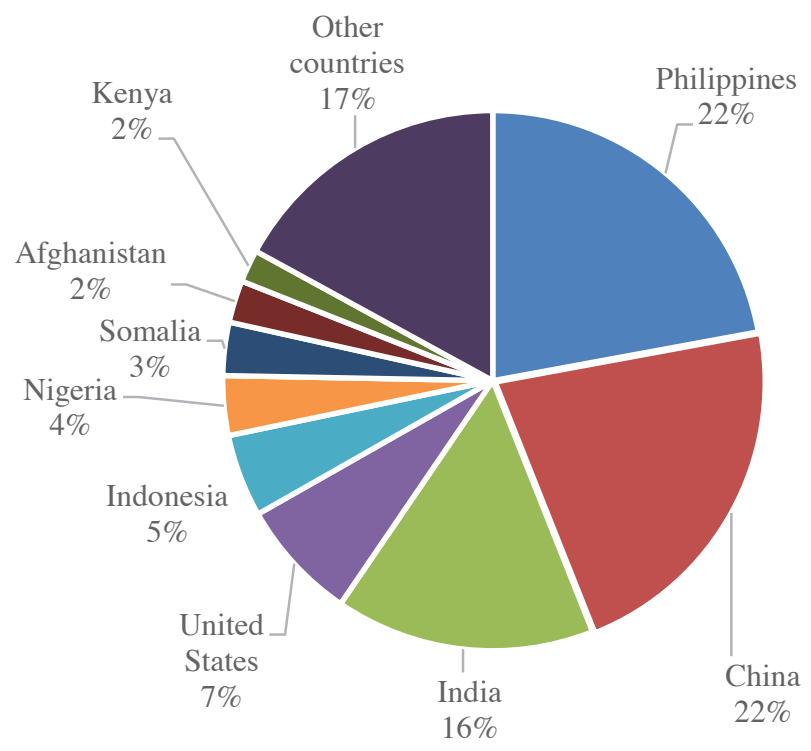

Fig. 3. The structure of the number of internal displacements of people relative to countries in 2018

Comparing the structure of the number of displacements by country, it is evident that there are countries for which the presence of environmental movement is a constant phenomenon. It applies in particular to the Philippines, India, the United States, China, and Indonesia. We can say that these countries suffer the most from natural disasters. Thus, population displacement due to catastrophes is a global issue that applies equally to both low-income and high-income countries.

During the period 2008-2019, 288.5 million people had to leave their homes due to natural disasters [48]. Figure 5 presents the dynamics of the number of new cases of internal displacement due to the catastrophe in 2008-2019. The highest values were recorded in 2008 and 2010.

An essential step in the study is to understand which catastrophes cause the most internal displacements. Data on the number of movements by type of disaster are presented in Table 1.

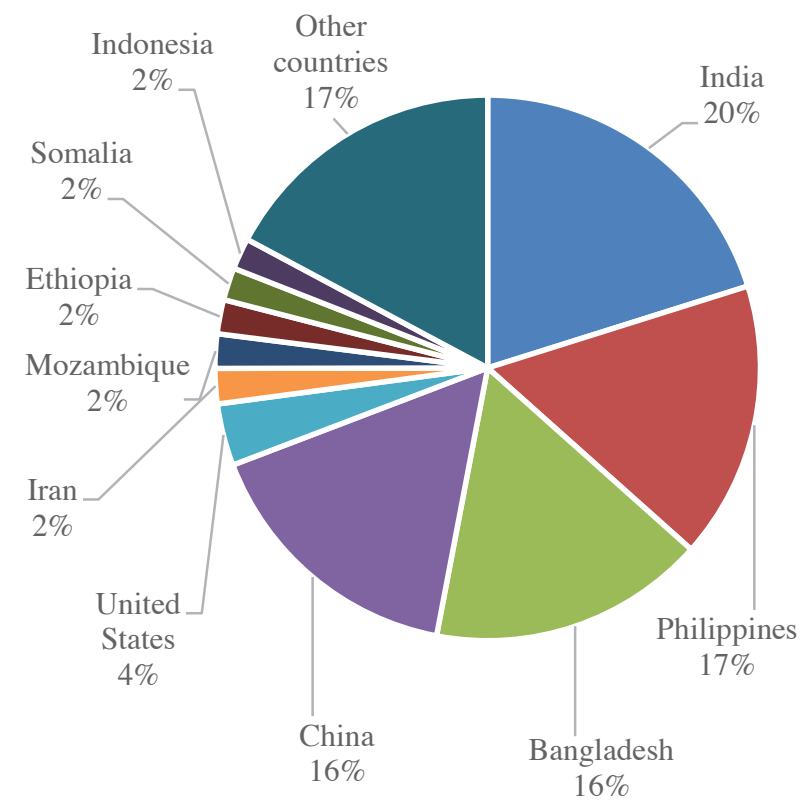

Fig. 4. The structure of the number of internal displacements of people relative to countries in 2019

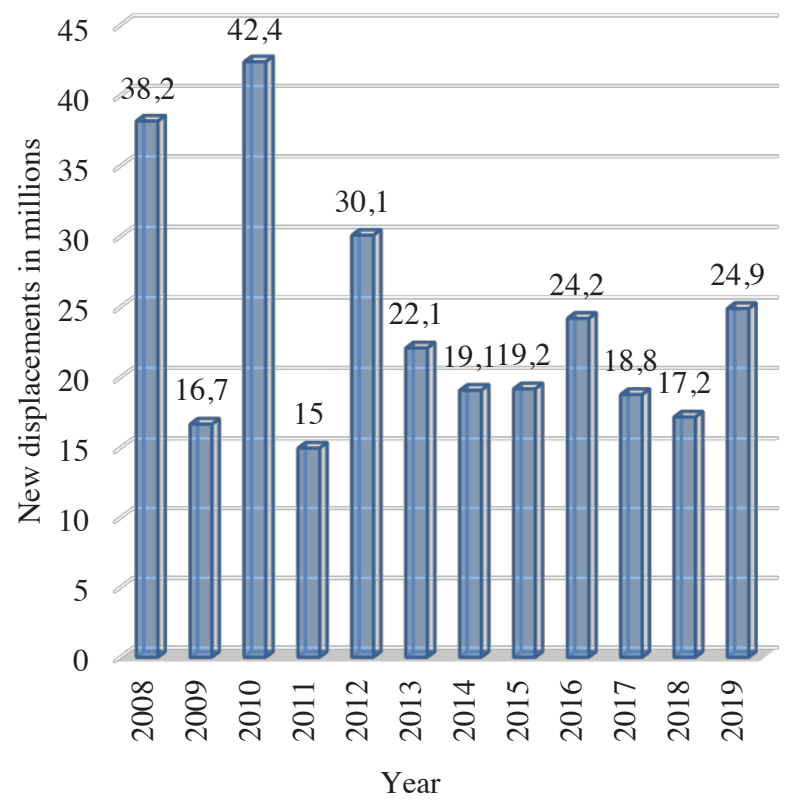

Fig. 5. Dynamics of new cases of internal displacement of people due to catastrophes for the period 2008-2019

As we can see from Table 1, almost $94 \%$ of human migrations due to the disaster in 2018 were related to weather changes, and only about $6 \%$ to geophysical phenomena. In 2019, about $96 \%$ of the movements were due to climatic factors. Thus, climate change is a major environmental factor pushing people to migrate. The main ones are storms (cyclones, hurricanes, typhoons) and floods; in 2019, the cases of displacement amounted to $52 \%$ and $40 \%$ of their total number, respectively. 
Thus, as we can see, to a greater extent, the internal migration of the population is caused by climatic factors.

Table 1. The number of recorded cases of internal displacement of people by type of disaster in 2018 and 2019

\begin{tabular}{|l|c|c|c|c|}
\hline \multirow{2}{*}{$\begin{array}{c}\text { Kind of } \\
\text { disasters }\end{array}$} & \multicolumn{2}{c|}{$\begin{array}{c}\text { Number of } \\
\text { displacements, } \\
\text { million }\end{array}$} & \multicolumn{2}{c|}{$\begin{array}{c}\text { \% of the total } \\
\text { displacements }\end{array}$} \\
\cline { 2 - 5 } & $\mathbf{2 0 1 8}$ & $\mathbf{2 0 1 9}$ & $\mathbf{2 0 1 8}$ & $\mathbf{2 0 1 9}$ \\
\hline $\begin{array}{l}\text { Total } \\
\text { displacements, } \\
\text { of which: }\end{array}$ & $\mathbf{1 7 . 2}$ & $\mathbf{2 4 . 9}$ & $\mathbf{1 0 0 . 0 0}$ & $\mathbf{1 0 0 . 0 0}$ \\
\hline $\begin{array}{l}\text { Weather } \\
\text { relared, } \\
\text { which: }\end{array}$ & $\mathbf{1 6 . 1}$ & $\mathbf{2 3 . 9}$ & $\mathbf{9 3 . 6 0}$ & $\mathbf{9 5 . 9 8}$ \\
\hline storms & 9.30 & 13.00 & 54.07 & 52.21 \\
\hline floods & 5.40 & 10.00 & 31.40 & 40.16 \\
\hline droughts & 0.76 & 0.28 & 4.42 & 1.12 \\
\hline wildfires & 0.42 & 0.53 & 2.44 & 2.13 \\
\hline landslides & 0.17 & 0.07 & 0.99 & 0.28 \\
\hline $\begin{array}{l}\text { extreme } \\
\text { temperatutes }\end{array}$ & 0.02 & 0.02 & 0.12 & 0.08 \\
\hline $\begin{array}{l}\text { Geophysical, } \\
\text { of which: }\end{array}$ & $\mathbf{1 . 1 0}$ & $\mathbf{0 . 9 5}$ & $\mathbf{6 . 4 0}$ & $\mathbf{3 . 8 2}$ \\
\hline earthguakes & 0.92 & 0.92 & 5.35 & 3.69 \\
\hline $\begin{array}{l}\text { volcanic } \\
\text { eruptions }\end{array}$ & 0.19 & 0.02 & 1.10 & 0.08 \\
\hline $\begin{array}{l}\text { dry mass } \\
\text { movement }\end{array}$ & 0.03 & - & 0.17 & - \\
\hline $\begin{array}{l}\text { mass } \\
\text { movements }\end{array}$ & 0.001 & - & 0.01 & - \\
\hline
\end{tabular}

Studies of Environmental migration have become widespread in recent decades. A rather big problem in the study of population migration is the lack of data on the full and diverse coverage of this phenomenon. It is especially true for developing cranes. Quite often, there was a situation of lack of data on internal or temporary movements of people, although such movements account for a significant share in Environmental migration. Of course, there are information resources that provide annual information on the number of new internal movements associated with rapid environmental disturbances (IDMC), but as for information on human mobility due to slow environmental changes (desertification, sea-level rise), its no more. There is also limited global data on transboundary movement in the event of a catastrophe, which significantly complicates the process of studying this phenomenon. Besides, there is a problem in estimating the economic and other costs associated with environmental migration. Therefore, it is impossible to thoroughly analyze the current state of Environmental migration, and given that this phenomenon is almost independent of man, it is difficult to predict his prospects.

\section{Conclusion}

In the course of the research, we analyzed Environmental migration. It has been found that this term describes the process of movement of people between territories due to environmental factors. In particular, it was found that the most common environmental factors of migration are storms and floods, which have caused more than $90 \%$ of new internal displacement in the last two years. The most typical Environmental migration is for Central Africa and Southeast Asia.

The study showed that the problem of Environmental migration is relevant based on its scale. Therefore, it is essential to develop and improve mechanisms to prevent the risks associated with environmental migration and minimize their negative consequences. Besides, it is necessary to improve the methods of collecting statistics related to environmental migration and migration in general, expanding their qualitative and quantitative composition, which will allow us to assess this process and improve its regulation mechanisms sufficiently.

\section{Acknowledgement}

The survey was supported by the Ministry of Education and Science of Ukraine, and performed the results of the projects $0118 \mathrm{U} 003569$ and 0120U102001.

\section{References}

1. S. Lyeonov, T. Pimonenko, Y. Bilan, D. Štreimikiene, G. Mentel, Energies. 12, 20. (2019) DOI: $10.3390 /$ en12203891

2. Y. Bilan, T. Vasilyeva, S. Lyeonov, K. Bagmet, Bus.: Theory \& Prac. 20. 103-115. (2019) DOI: 10.3846/BTP.2019.10.

3. T. Vasilyeva, S. Bilan, K. Bagmet, R. Seliga, Econ. \& Soc. 13, 1. 271-294. (2020) DOI: 10.14254/2071789X.2020/13-1/17.

4. V. Levchenco, A. Boyko, V. Bozhenko, S. Mynenko, Bus.: Theory \& Prac. 20. 492-508. (2019) DOI: 10.3846/btp.2019.46.

5. I. Kendiukhov, M. Tvaronaviciene, MMI. 3. 33-42. (2017) DOI: 10.21272/mmi.2017.3-03

6. Y. Bilan, T. Vasilyeva, O. Lyulyov, T. Pimonenko, Int. J. Bus. \& Soc. 20, 2. 433-450. (2019) URL: http://www.ijbs.unimas.my/images/repository/pdf/V ol20-no2-paper1.pdf.

7. Y. Bilan, A. G. Raišienè, T. Vasilyeva, O. Lyulyov, T. Pimonenko, Pub. Pol. \& Adm. 18, 2. 241-255. (2019) DOI: 10.13165/VPA-19-18-2-05

8. S. Pryima, Y. Dayong, O. Anishenko, Y. Petrushenko, A. Vorontsova, Probl. \& Perspect. Manag. 16, 3. 1-13. (2018) DOI: 10.21511/ppm.16(3).2018.01

9. H. Dkhili, MMI. 3. 333-344. (2018) http://doi.org/10.21272/mmi.2018.3-30

10. Y. Bilan, S. Lyeonov, N. Stoyanets, A. Vysochyna, IJETM. 21， 5-6. 289-305. (2018) DOI: 10.1504/IJETM.2018.100580

11. O. Lyulyov, T. Pimonenko, N. Stoyanets, N. Letunovska, Res. World Econ. DOI: 10.5430/rwe.v10n4p97.

12. Y. Bilan, S. Lyeonov, T. Vasylieva, Y. Samusevych, Online J. Model. the New Europe. 27. 34-66. (2018) DOI: 10.24193/OJMNE.2018.27.02 
13. Y. Bilan, P. Rubanov, T. Vasylieva, S. Lyeonov, Pol. J. Manag. Stud. 19, 1. 70-93. (2019) DOI: 10.17512/pjms.2019.19.1.06

14. Y. Bilan, M. Brychko, A. Buriak, T. Vasilyeva, Zb. Radova Ekon. Fak. au Rijeci. 37, 1. 113-138. (2019) DOI: $10.18045 /$ zbefri.2019.1.113

15. Y. Bilan, T. Vasilyeva, O. Kryklii, G. Shilimbetova, Creat. Stud. 12, 1. 75-101. (2019) DOI: 10.3846/cs.2019.7453

16. Y. Bilan, S. Lyeonov, O. Lyulyov, T. Pimonenko, Pol. J. Manag. Stud. 19, 2. DOI: 10.17512/pjms.2019.19.2.05.

17. Y. M. Petrushenko, N. M. Kostyuchenko, Y. I. Danko, Act. Probl. Econ. 159, 9. 257-263. (2014).

18. H. Shvindina, Safety. 5, 3. (2019) DOI: 10.3390/safety503006

19. V. Faifura, Reg. Asp. Prod. Forces Dev Ukraine. 17. 44-48.

20. Parliamentary Assembly, Environmentally induced migration and displacement: a 21st century challenge. Report. 23 December 2008. (2009)

21. IOM: Migration and the Environment. Discussion Note: $\mathrm{MC} / \mathrm{INF} / 288$, prepared for the Ninety-fourth Session of the IOM Council, 27-30 November 2007, Geneva (2007)

22. P. Baofu, The Future of Post-Human Migration: A Preface to a New Theory of Sameness, Otherness, and Identity (Cambridge Scholars Publishing, 2012)

23. UNOCHA: Guiding principles on Internal Displacement. August 1998. (1998)

24. R. Brizmohum, Nat. Resour. Forum. 43, 3. 154-163. (2019) DOI: 10.1111/1477-8947.12172

25. C. Jacobcon, S. Crevello, C. Chea, B. Jarihani, Reg. Environ. Change. 19, 1. 101-112. (2019) DOI: $10.1007 / \mathrm{s} 10113-018-1387-6$

26. J. Busby, Curr. Clim. Change Rep. 4, 4. 338-346. (2018) DOI: $10.1007 / \mathrm{s} 40641-018-0116-\mathrm{z}$

27. J. Luetz, Climate Change Management (Springer, 2018) DOI: 10.1007/978-3-319-64599-5_5

28. W. F. G. Cardy, Human Impact on Environment and Sustainable Development in Africa (Taylor and Francis, 2018) DOI: 10.4324/9781315192963-7

29. A. Anurag Danda, N. Ghosh, J. Bandyopadhyay, S. Hazra, J. Indian Ocean Reg. 15, 3. 317-335. (2019) DOI: 10.1080/19480881.2019.1652974

30. R. M. Pink, The Climate Change Crisis: Solutions and Adaption for a Planet in Peril (Springer International Puplishing, 2018) DOI: 10.1007/978-3319-71033-4

31. P. Aniah, M. Kaunza-Nu-Dem, J. Ayembilla, Heliyon. 5, 4. (2019) DOI: 10.1016/j.heliyon.2019.e01492

32. Z. Zommers, K. Alverson, Resilience: The Science of Adaptation to Climate Change (Elsevier, 2018) DOI: $10.1016 / C 2016-0-02121-6$
33. M. J. Bush, Climate Change Adaptation in Small Island Developing States (Wiley Blackwell, 2017) DOI: $10.1002 / 9781119132851$

34. R. Ahsan, South Asia Res. 39, 2. 184-201. (2019) DOI: $10.1177 / 0262728019842968$

35. H. Dave, Bus. Ethics and Leadersh. 1, 2, 78-87. (2017) DOI: 10.21272/bel.1(2).78-88.2017

36. U. Kolomiiets, Yu. Petrushenko, Socioecon. Chall. 1, 1. 77-80. (2017) http://doi.org/10.21272/sec.2017.109

37. F. A. Galgano, Advances in Military Geosciences (Springer, 2019) DOI: 10.1007/978-3-319-909752_9

38. E. Seiyefa, Afr. Secur. Rev. DOI: $10.1080 / 10246029.2019 .1697308$

39. F. Ali, T. A. Khan, A. Alamgir, M. A. Khan, Earth Syst. Environ. 2, 3. 573-599. (2018) DOI: $10.1007 / \mathrm{s} 41748-018-0080-8$

40. C. Cattaneo, V. Bosetti, CESifo Econ. Stud. 63, 4. 500-528. (2017) DOI: 10.1093/cesifo/ifx010

41. B. Germond, F. W. Ha, J. Environ. Stid. Sciences. 9, 1. (2019) DOI: 10.1007/s13412-018-0509-2

42. L. English, P. Mayo, Int. Rev. Edu. 65, 2. 213-231. (2019) DOI: 10.1007/s11159-018-9757-3

43. I. Makarenko, Bus. Ethics and Leadersh. 1, 1. 16-24. (2017) DOI: 10.21272/bel.2017.1-02

44. I. Aliyas, E. Ismail, M. Alhadeedy, Socioecon. Chall. 2, 2. 75-80. (2018) DOI:10.21272/sec.2(2).7580.2018

45. S. N. Singh, Socioecon. Chall. 2, 2, 41-48. (2018) DOI: $10.21272 / \mathrm{sec} .2(2) .41-48.2018$

46. C. P.O. Reyer. I. M. Otto, S. Adams, T. Albrecht ant others, Reg. Environ. Change. 17, 6. 1639-1650. (2017) DOI: 10.1007/s10113-015-0893-z

47. IDMC: Global Report on Internal Displacement. GRID 2018. May 2019 (2019)

48. IDMC: Global Report on Internal Displacement. GRID 2019. April 2020 (2020) 